\title{
ALTERNATIVE MENTORING FOR PSYCHOLOGY STUDENTS
}

\author{
Laura Chesniak-Phipps, Grand Canyon University \\ Laura Terry, Grand Canyon University
}

\begin{abstract}
The ratio of full-time psychology faculty to psychology students on a college campus can often present difficulty in providing individual mentoring. Further, because psychology students can apply their degrees in a variety of ways, mentoring is a critical component to success post-graduation, whether a student chooses to pursue a career or graduate school. In response to this issue, two, full-time psychology professors created and implemented a mentoring program in an attempt to reach undergraduate students in a group setting. This paper will outline the pilot semester of the program and discuss implications for
\end{abstract} future programs.

According to the National Center for Education Statistics (2018), there were 118,000 psychology degrees conferred at the bachelor's level in 20142015, making it one of the most popular majors on college campuses. Recent trends have reported psychology baccalaureates growth dropping for the first time in years, from 125,759 graduates in 2016 to 124,497 graduates in 2017 (Christidis, Lin, \& Conroy, 2019). However, this is still a large number of students. The vast number of students who major in psychology can present a challenge for full-time faculty who are trying to provide guidance and mentoring. Students, who actively seek faculty guidance are often the only ones who receive mentoring, and typically, these students are the ones who plan to attend graduate school. Not every student is bound for graduate school and will graduate looking for employment directly after completing their undergraduate degree. Psychology majors who do not pursue a degree beyond the bachelor's level are referred to as workforce graduates and comprise about $75 \%$ of the field (Landrum \& McCarthy, 2018). These workforce graduates need to fully understand the skills the developed through their undergraduate studies, be able to articulate them to others, and market themselves for career success.

Psychology majors are in a unique position in that their degree can prepare them for numerous career paths. According to the American Psychological Association (2011), individuals with a bachelor's degree in psychology work in varied fields, including education, business, sales, health, and the service industry. Psychology graduates are employed in the mental health arena, health care, and business, among others (APA, 2011). In 2017, it was estimated that $1,910,800$ individuals held a bachelor's degree in psychology as their highest degree. Of that number, $72 \%$ reported being employed and represented 92 of 129 different workplace categories (APA, 2018). Further, $62 \%$ of those believed their jobs were related to psychology, and $27 \%$ believed their jobs were closely related to psychology (APA, 2018). This is one of the exciting, and yet overwhelming, characteristics of a psychology degree. Unlike a student who graduates with a nursing degree and pursues employment as a nurse upon graduating, a psychology student has various options. This is a benefit, but often times the applicability of the degree can also be overwhelming and confusing, both for the graduate and potential employers. If students do not receive proper and consistent mentoring, they may leave their undergraduate education feeling overwhelmed and lost in terms of where and how to look for employment. According to Halonen (2019), graduates need to be able to identify their choices and help those in the 
career they choose to pursue understand how their degree in psychology will support the work they are applying to do. By developing a workplace lens and thinking about the applicability of each course they completed, they will be prepared to articulate the value they can bring a company.

In a previous paper, Terry and Chesniak-Phipps (2018) discussed the importance of a Capstone class, and they reported that many of psychology students were not receiving career mentoring until their last semester of college. By their senior year, many students had not given much thought to how they would apply their psychology degree to a future career path. In learning this, it became clear that better way to reach students earlier in their academic career was necessary. However, the reality of reaching students individually was unrealistic. Therefore, a mentoring program was developed and implemented in group settings. This paper will discuss the pilot of the program, which was called The College to Career Series, and propose directions for future direction and implementation.

\section{GROUP MENTORING PROGRAM}

Curriculum for this problem was developed by Chesniak-Phipps and Terry, based on information from the American Psychological Association's (APA) website and the book, The Psychology Major's Companion. Everything you need to know to get you where you want to go (Dunn \& Halonen, 2017).

Participants were recruited through advertisements posted on campus and word of mouth from instructors. Students were able to attend any or all of the sessions. Four sessions were available for participants to attend. The curriculum was developed and implemented by Chesniak-Phipps and Terry at the university. All sessions began with a Power Point presentation and then included hands-on activities to engage the participants and help them apply the information that was being presented in the lessons. Sessions concluded with a question and answer time, and during the last 15 minutes participants were able to interact with the professors on a one-on-one basis if they chose.

Session 1 focused on the workplace advantage based on information from APA's website and an activity from the textbook. During this session, students applied workplace advantages they had achieved. The goal was to assist students in learning to articulate orally and in writing the workplace skills they were learning in their academic career and to understand how these would help them to prepare for the workplace.

Session 2 examined employable skills and gaining experience while still in school. The purpose of this session was to help students understand the specialized skills they had as psychology majors so that they may communicate them effectively to potential employers. Participants completed the Employable Skills Self-Efficacy Survey (ESSES) (Ciarocco \& Strohmetz, 2017) online and examined which areas they excelled in and which areas they needed to strengthen. Students were instructed to read the feedback provided and outline a plan for increasing their deficits. Students were also exposed to internship and volunteer opportunities that they could participate in.

During Session 3, the importance of a professional online presence was discussed. Students were given information on how to create professional resumes and were taught how to make their online presence more professional. Proper networking etiquette was discussed. Finally, students were taken through the steps for creating a Linked-In account that would draw the attention of future employers.

The final session concentrated on understanding the different types of graduate degrees, steps necessary to obtain admission to graduate school, and information on the GRE should this be the path that they pursue.

\section{FUTURE DIRECTIONS}

The students who attended the programs provided positive feedback on the sessions; however, a small number of students in attendance suggested there might be a better way to reach more students. Because the sessions took place midday, it is possible that students did not attend as readily due to club meetings, preparing for classes, or other engagements. They may also not have been aware that these sessions were being offered. In the future, delivering these sessions as part of the curriculum in psychology courses is recommended. In the next installation of the mentoring program, faculty are planning to implement the curriculum in a classroom setting. This would confirm that all 
four sessions are delivered to the same students. Further, implementing the curriculum in a 200- or 300 -level class would ensure students receive this information early in their academic career and that all psychology majors receive this information during their collegiate career.

Another avenue that could be utilized is creating a digital mentoring program that would be made available to students. While more students were reached than would have been in a one-onone traditional mentoring relationship, this pilot still only reached a small number of psychology majors. Expanding this to deliver mentoring to all our students is a future goal. One way that this can be done is by creating digital mentoring content that can be delivered to all psychology students on the traditional ground campus as well as to online students.

In any program, assessment is an important component. Therefore, outcome measures should be developed and implemented to ensure that the topics taught in the sessions are having a direct impact on employment readiness.

This model could also be adapted to fit other majors who may have career paths that diverge. Many of the students in humanities majors such as English, Math, and History will find they can apply their degree in a myriad of ways. Therefore, ensuring they know how to do this is imperative.

The pilot mentoring program for psychology majors was an attempt to provide career and postgraduation guidance to students in a group setting. Takeaway lessons from this pilot are guiding and improving future implementations of the program. Ideally, more students can be mentored through this program to help successfully launch them into their future careers. 


\section{REFERENCES}

American Psychological Association. (2011). Careers in psychology. Retrieved from http://www.apa.org/careers/ resources/guides/careers.aspx

American Psychological Association. (2018). Careers in psychology. [Interactive data tool]. Retrieved from http://www. apa.org/workforce/data-tools/careers-psychology.aspx

Terry, L., \& Chesniak-Phipps, L. (2018). Preparing psychology undergraduates for the future. Journal of Scholarly Engagement. 1(2), 24-31.

Christidis, P., Lin, L., \& Conroy, J., (2019). The growth of psychology baccalaureates slows. Monitor on Psychology, 50(5), 21.

Ciarocco, N. J., \& Strohemtz, D. B. (2017). The employable skills self-efficacy survey: An assessment of and resource for fostering skill development. Society for Teaching of Psychology. Retrieved from http://teachpsych.org/resources/ Documents/otrp/resources/Ciarocco_intructor_resource_ FINAL.docx

Dunn, D. S., \& Halonen, J. S. (2017). The psychology major's companion: Everything you need to know to get where you want to go. New York, NY: Worth Publishers.

Halonen, J. (2019). Defending the major: Exploiting the workforce advantage of the psychology degree. American Psychological Association's Psych Learning Curve. Where psychology and education connect. Retrieved from http://psychlearningcurve. org/defending-the-psychology-major/

Landrum, R. E., \& McCarthy, M. A. (2018). Measuring the benefits of a bachelor's degree in psychology: Promises, challenges, and next steps. Scholarship of Teaching and Learning in Psychology, 4(1), 55-63. doi-org.lopes.idm.oclc.org/10.1037/ stl0000101

U.S. Department of Education, National Center for Education Statistics. (2018). Digest of Education Statistics, 2016 (NCES 2017-094) Chapter 3. Retrieved from https://nces.ed.gov/ 